\title{
Acceleration in the Repair and Regenerative Responses by Different Doses of Hesperidin in the Deep Full Thickness Cutaneous Wound of Mice Whole Body Exposed To 6 Gy of $\gamma$-Radiation
}

\author{
Jagetia $\mathrm{GC}^{1 *}$ and Rao KVNM${ }^{2}$ \\ 110 Maharana Pratap Colony, India \\ 2Department of Biochemistry, GSL Medical College, India
}

*Corresponding author: Ganesh Chandra Jagetia, 10, Maharana Pratap Colony, Sector-13, HiranMagri, Udaipur-313002, India, Email: gc.jagetia@gmail.com

\section{Research Article \\ Volume 2 Issue 3}

Received Date: April 09, 2018

Published Date: May 08, 2018

\section{Abstract}

Ionizing radiations are necessary evil as everyone is exposed to them intentionally for diagnostic purposes or unintentionally from cosmic sources or background radiations. Ionizing radiations are known to cause adverse health effects at low to moderate doses whereas high doses are fatal. One of the adverse effects of ionizing radiations is the retardation of wound healing. We have studied the effect of different doses of hesperidin on the wound contraction in mice whole body exposed to 6 Gy of $\gamma$-irradiation. The mice were administered orally with a single dose of $0,10,20,50$, $100,200,250$ or $500 \mathrm{mg} / \mathrm{kg}$ of hesperidin one hour before exposure to $6 \mathrm{~Gy}$ of $\gamma$-radiation. After 10 minutes of irradiation a full-thickness skin wound was produced on the dorsum of Swiss albino mice receiving various doses of hesperidin or not before exposure to 6 Gy $\gamma$-radiations. Assessment of wound contraction was carried out by capturing the video images of the wound on different post-irradiation days until complete healing of wounds and the mean wound healing time was determined by daily monitoring the progress of wound healing until complete closure of wounds. Administration of 10 to $500 \mathrm{mg} / \mathrm{kg}$ body weight of hesperidin resulted in a dose-dependent increase in the wound contraction when compared with non-drug treated control. A highest but significant wound contraction was observed for $100 \mathrm{mg} / \mathrm{kg}$ hesperidin at all the post-irradiation days. A complete healing of wounds was observed by day 16 postirradiation in the hesperidin treated sham-irradiation group when compared to day 18.7 sham-irradiation group. The whole-body exposure of mice to 6 Gy of $\gamma$-radiation caused a significant delay in wound contraction and increased the mean wound healing time when compared to untreated control animals. Administration of different doses of hesperidin before 6 Gy irradiation progressively increased wound contraction and a maximum effect was observed at $100 \mathrm{mg} / \mathrm{kg}$ thereafter the effect was lesser than $100 \mathrm{mg} / \mathrm{kg}$ hesperidin. A similar effect was observed on mean wound healing time where the wound healing time was reduced by approximately two days when compared to irradiation alone. Our study demonstrates that hesperidin enhances the wound contraction and reduces the mean wound healing time. 
Keywords: Radiation; Hesperidin; Mice; Excision wound; Contraction; Mean wound healing time

Abbreviations: DNA: Deoxyribonucleic Acid; ROS: Reactive Oxygen Species; HPD: Hesperidin; CMC: Carboxymethylcellulose; MHT: Mean Healing Time.

\section{Introduction}

A new era had begun with the discovery of X-rays by Wilhelm Conrad Roentgen in 1885 in modern science and healthcare. Since, then research in nuclear materials, science and technology led to the increased use of nuclear materials for various applications in industry, medicine, science, military and nuclear facilities. The proliferation of radioactive materials in various specialties has increased the likelihood of accidental/intentional exposure to ionizing radiation. In medical field the, ionizing radiations have emerged as a powerful tool for the disease diagnosis and treatment of cancer or other similar conditions preoperatively, postoperatively, or as a sole treatment modality to treat cancer [1-3]. As many as half of all cancer patients receive some form of radiation treatment and despite improvements in radiation techniques, patients still experience adverse side effects of radiation $[4,5]$. The acute radiation exposure coupled with combined injuries in the form of superimposed skin wounds and/or burn injury produce serious clinical problems. Combined injuries can also arise from nuclear accidents of Chernobyl and Fukushima type, atomic bomb explosion and release of radioactive materials by terror outfits [6-8]. Irradiation along with other injuries acts synergistically, resulting in much greater morbidity and/or mortality than the radiation injury alone [10-13].

For most patients, wounds heal naturally as the body works to heal itself. Yet for those whose healing process is delayed or complicated by other conditions, such as age, body size, chronic disease, nutritional status, vascular insufficiencies, immunosuppressant and radiation therapy, the wound site becomes a medical problem leading to delayed healing or chronic non-healing wounds that require specialized treatment and care [13-15]. Interaction of ionizing radiation with wounded tissue disrupts normal responses to injury leading to a protracted recovery period. Ionizing radiations cause damage to various tissues by means of energy transfer that generates highly reactive chemical products known as free radicals, which can subsequently combine with normal body chemicals and react with cellular components, leading to intracellular and molecular damage [16]. The primary targets of cell damage are cellular and nuclear membranes and deoxyribonucleic acid (DNA). The skin cells suffer from the cytotoxic effects of reactive oxygen species (ROS), generated from the interaction between ionizing radiation and water molecules in the cells leading to loss of function of skin as a protective barrier over the body surface [17]. Other events associated with the phase of oxidative stress response in the skin are depletion of endogenous intra and intercellular antioxidants, enhancement of intracellular lipid peroxidation and the induction of specific signal transduction pathways that can modulate inflammatory, immune suppressive or apoptotic processes in the skin that could be detrimental to the normal functioning of the skin. To modulate the redox (antioxidant/pro-oxidant) balance in vivo, there is a general need for safe and effective antioxidants/skin protectants. Consequently, supplementation with exogenous antioxidants that scavenge ROS and restore normal redox state may be beneficial in such cases [1821].

Lebreton was the first to discover hesperidin in the year 1827 in an impure state and it has been investigated for its various properties since then [22]. Hesperidin also known as hesperitin-7-rhamnoglucoside or hesperitin-7rutinoside is synthesized mainly by citrus plants as secondary metabolite. It is present in the discarded rinds of the ordinary orange Citrus aurantium L.C. sinensis, C. unshiu and other species of the Citrus genus [23-26]. Hesperidin plays an important role in plant defense and the pulpy orange juice contains higher amount of hesperidin than the juice without pulp. Sweet oranges (Citrus sinensis) and tangelos contain larger amount of hesperidin [27]. The analgesic, antiatherogenic, antiinflammatory, antibacterial, antioxidant, antiradical, diuretic, antiulcer and antiviral properties of hesperidin have been intensively studied in various study systems [24,28-31].

Hesperidin improves capillary permeability and increases their strength [32]. It facilitates vitamin $C$ in keeping collagen in healthy condition and it is also required for absorption and use of vitamin C. Hesperidin inhibits oxidation of vitamin $\mathrm{C}$ in the body and is useful in hypertension. It prevents haemorrhages and helps in conditions of ruptured capillaries and connective tissues and builds a protective barrier against infections [33]. Hesperidin is an anti-cancerous, anti-microbial, antiallergenic, anti-hypotensive, anti-proliferative and a vasodilator [34-39]. Hesperidin has been found to be 


\section{Nursing \& Healthcare International Journal}

hypolipidemic in humans and retard bone loss $[40,41]$. Hesperidin alleviates hypotension, oxidative stress, nitric oxide synthase activity, and neurotoxicity. Hesperidin is active against Herpes simplex virus, inflammatory bowel disease, arthritis, platelet and erythrocyte aggregation and infection $[24,26,28,42-44]$. The sub chronic administration of $5 \%$ hesperidin for 13 weeks has been found to be non-toxic in mice [45]. Hesperidin has been found to be non-toxic in animals and humans [31,45]. The present study was undertaken to obtain an insight into the effect of different doses of hesperidin on the healing of deep dermal excision wound in mice exposed to $6 \mathrm{~Gy}$ whole-body $\gamma$-radiation.

\section{Materials and Methods}

The animal care and handling were carried out according to the guidelines of the World Health Organization, Geneva and the INSA (Indian National Science Academy, New Delhi). Eight to ten weeks old Swiss albino mice of either sex weighing 30 to $36 \mathrm{~g}$ were selected from an inbred colony maintained under the controlled conditions of temperature $\left(23 \pm 2^{\circ} \mathrm{C}\right)$, humidity $(50 \pm 5 \%)$ and light (12 h of light and dark, respectively). The animals were given free access to sterile food and water. The food consisted of $50 \%$ cracked wheat, $40 \%$ Bengal grams, $4 \%$ milk powder, $4 \%$ yeast powder, $0.75 \%$ sesame oil, $0.25 \%$ cod liver oil, and $1 \%$ salt. Four animals were housed in a polypropylene cage containing sterile paddy husk (procured locally) as bedding. The study was approved by the institutional animal ethical committee of the Manipal University, Manipal, India.

\section{Preparation of Drug and Mode of Administration}

Hesperidin (HPD) was procured from Acros Organics, Geel, Belgium. Since it is sparingly soluble in water the required amount of (HPD) was suspended in 1\% carboxymethylcellulose (CMC) immediately before administration to the animals. The animals were administered with a single dose of $0.01 \mathrm{ml} / \mathrm{g} \mathrm{b}$. wt. of CMC or HPD orally through an oral gavage before irradiation.

\section{Experimental Design}

This experiment was carried out to evaluate the effect of various doses of hesperidin on wound healing in the irradiated wounds of mice, where the animals were divided into the following groups: -

CMC+sham-irradiation: The animals of this group received $0.01 \mathrm{ml} / \mathrm{g}$ body weight of $1 \% \mathrm{CMC}$ before (0 Gy) sham-irradiation.
HPD +sham-irradiation: The animals of this group received $10,20,50,100,200,250$ or $500 \mathrm{mg} / \mathrm{kg}$ body weight of hesperidin before sham-irradiation.

CMC+irradiation: The animals of this group were administered with $0.01 \mathrm{ml} / \mathrm{g}$ body weight of $1 \% \mathrm{CMC}$ before 6 Gy irradiation.

HPD +irradiation: This group of animals was given 10, $20,50,100,200,250$ or $500 \mathrm{mg} / \mathrm{kg}$ body weight of hesperidin before 6 Gy irradiation.

\section{Irradiation}

One hour after the administration of CMC or hesperidin, each animal was placed into a specially designed well-ventilated acrylic restrainer and the whole body of the prostrate and immobilized animals was exposed to 0 or 6 Gy of $\gamma$-radiation, given at a dose rate of $1.35 \mathrm{~Gy} / \mathrm{min}$ from a ${ }^{60} \mathrm{Co}$ Teletherapy source (Theratron, Atomic Energy Agency, Ontario, Canada).

\section{Production of Full-Thickness Skin Wound}

The fur of the dorsum (below the rib cage) of each animal was removed with a cordless electric mouse clipper (Wahl Clipper Corporation, Illinois, USA) before exposure to 6 Gy $\gamma$-radiation and a full-thickness deep dermal excision wound was created on the dorsum (below the rib cage) of each animal within ten minutes of irradiation [31]. Briefly, the animals were anesthetized and the skin of the entire body was cleaned and decontaminated by wiping the whole body with sterillium (Bode Chemical Co. Hamburg, Germany) disinfectant solution. The cleared dorsal surface of the skin was marked with a sterile circular (15-mm-diameter) stainless steel stencil. A full-thickness cutaneous wound was created by excising the skin flap including penniculus carnosus in an aseptic environment using sterile scissors and forceps. Each wounded animal was housed in an individual sterile polypropylene cage.

\section{Measurement of Wound Contraction}

Wound contraction was monitored by capturing the video images of each full-thickness wound with a CCD camera connected to a computer [31]. The first image of each wound from different groups was obtained one day after wounding, and that day was considered as day one. The subsequent images were captured on 3, 6, 9, 12 and 15 days post wounding. The wound area was calculated using Auto CAD R14 (Autodesk Inc., San Rafael, CA) software. Eight animals were used in each group at each 


\section{Nursing \& Healthcare International Journal}

drug dose and a total of 128 animals were used for this experiment.

\section{Mean Wound Healing Time}

A separate experiment was performed to evaluate the effect of various doses of hesperidin on the mean healing time (MHT) after exposure to 0 or 6 Gy whole-body $\gamma$ radiation except that no attempt was made to capture the video images after wounding (for details see above). All the animals in each group were monitored until complete healing of wounds visually and the day at which each wound closed completely was recorded. The mean of all the days was considered as mean wound healing time and expressed in days. Eight animals were used in each group at each drug dose and a total of 128 animals were used for this experiment.

\section{Analysis of Data}

Statistical significance between the treatments was determined using one-way ANOVA. The Solo 4 Statistical Package (BMDP Statistical Software Inc., Los Angeles, CA, USA) was used for data analysis. All data are expressed as mean \pm SEM (Standard error of mean).

\section{Results}

The results of wound contraction and mean wound healing time are presented in Figures 1-8.

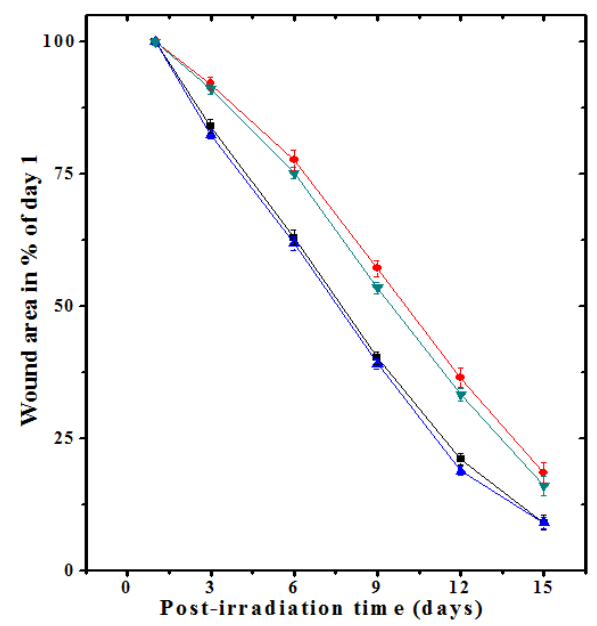

Figure 1: Acceleration of healing of deep cutaneous excision wound in mice treated with $10 \mathrm{mg} / \mathrm{kg}$ body weight hesperidin before exposure to $6 \mathrm{~Gy}$ of $\gamma$ radiation.

Squares: Carboxymethylcellulose; Circles: Hesperidin; Up triangles: Carboxymethylcellulose +Irradiation and Down triangles: Hesperidin +Irradiation.

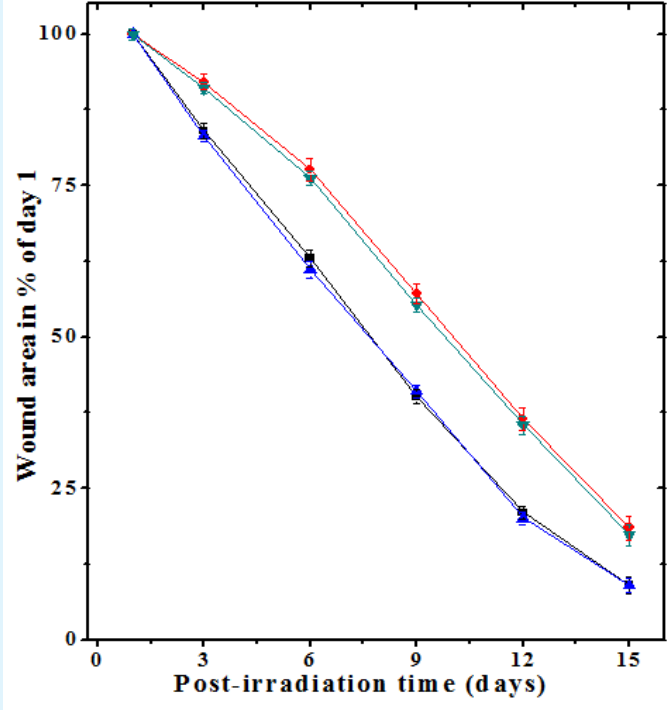

Figure 2: Acceleration of healing of deep cutaneous excision wound in mice treated with $20 \mathrm{mg} / \mathrm{kg}$ body weight hesperidin before exposure to $6 \mathrm{~Gy}$ of $\gamma$ radiation.

Squares: Carboxymethylcellulose; Circles: Hesperidin; Up triangles: Carboxymethylcellulose +Irradiation and Down triangles: Hesperidin +Irradiation.

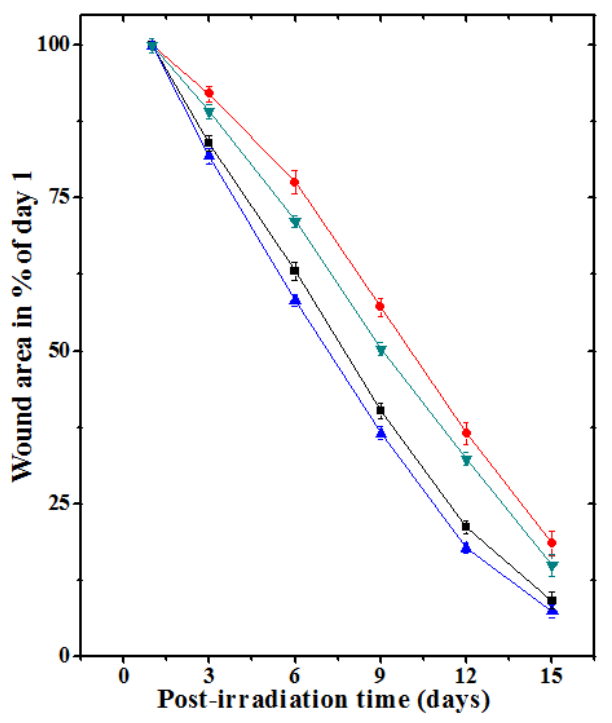

Figure 3: Acceleration of healing of deep cutaneous excision wound in mice treated with $50 \mathrm{mg} / \mathrm{kg}$ body weight hesperidin before exposure to $6 \mathrm{~Gy}$ of $\gamma$ radiation.

Squares: Carboxymethylcellulose; Circles: Hesperidin; Up triangles: Carboxymethylcellulose +Irradiation and Down triangles: Hesperidin +Irradiation. 


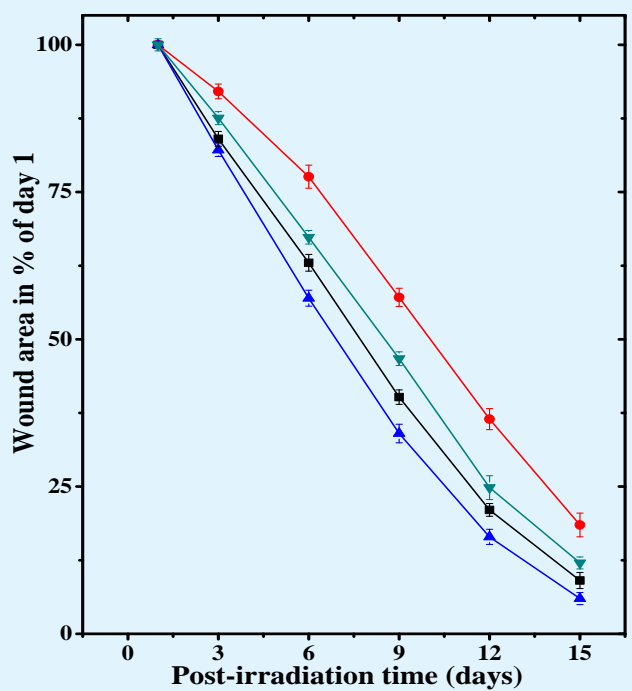

Figure 4: Acceleration of healing of deep cutaneous excision wound in mice treated with $100 \mathrm{mg} / \mathrm{kg}$ body weight hesperidin before exposure to $6 \mathrm{~Gy}$ of $\gamma$ radiation.

Squares: Carboxymethylcellulose; Circles: Hesperidin; Up triangles: Carboxymethylcellulose +Irradiation and Down triangles: Hesperidin +Irradiation.

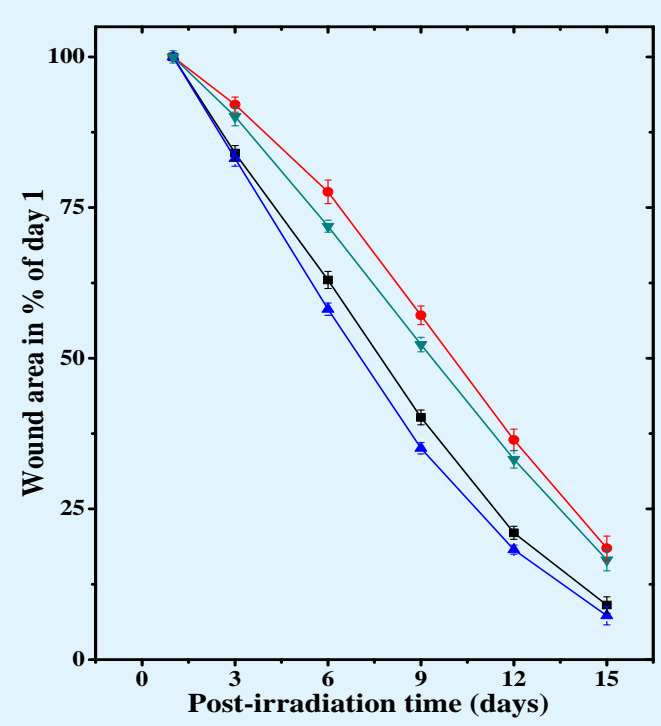

Figure 5: Acceleration of healing of deep cutaneous excision wound in mice treated with $200 \mathrm{mg} / \mathrm{kg}$ body weight hesperidin before exposure to $6 \mathrm{~Gy}$ of $\gamma$ radiation.

Squares: Carboxymethylcellulose; Circles: Hesperidin; Up triangles: Carboxymethylcellulose +Irradiation and Down triangles: Hesperidin +Irradiation.

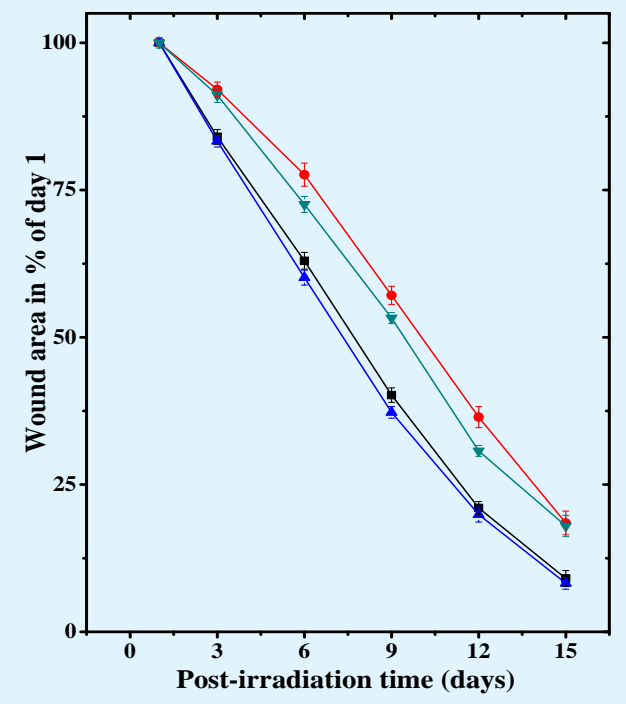

Figure 6: Acceleration of healing of deep cutaneous excision wound in mice treated with $250 \mathrm{mg} / \mathrm{kg}$ body weight hesperidin before exposure to $6 \mathrm{~Gy}$ of $\gamma$ radiation.

Squares: Carboxymethylcellulose; Circles: Hesperidin; Up triangles: Carboxymethylcellulose +Irradiation and Down triangles:Hesperidin +Irradiation.

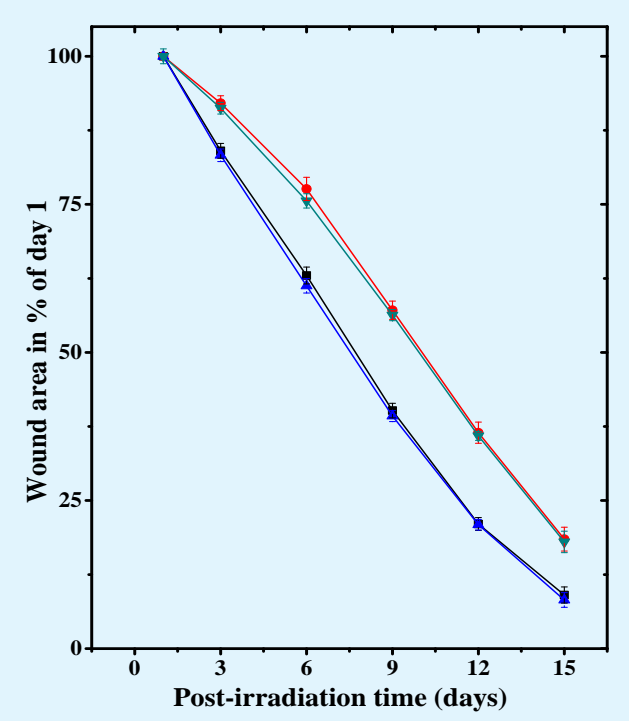

Figure 7: Acceleration of healing of deep cutaneous excision wound in mice treated with $500 \mathrm{mg} / \mathrm{kg}$ body weight hesperidin before exposure to $6 \mathrm{~Gy}$ of $\gamma$ radiation.

Squares: Carboxymethylcellulose; Circles: Hesperidin; Up triangles: Carboxymethylcellulose +Irradiation and Down triangles: Hesperidin +Irradiation. 


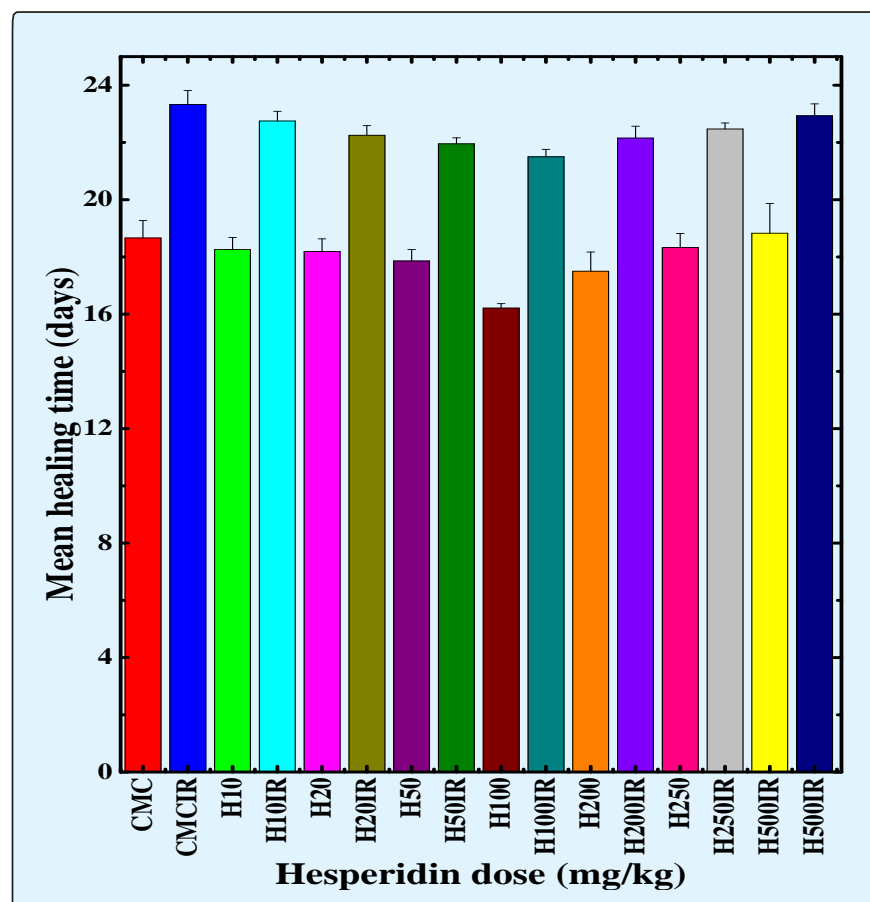

Figure 8: Alteration in the mean wound healing time of deep cutaneous excision wound in mice treated with different doses of hesperidin before exposure to $6 \mathrm{~Gy}$ of $\gamma$-radiation.

\section{Wound Contraction}

The progression of the healing of excision wounds can be evaluated by the periodic assessment of wound contraction. The area of each wound at a specific time has been expressed as the percentage of its original size on day one and the data are represented in Figures 1-7. Determination of wound contraction by capturing video images at different times after irradiation revealed a continuous contraction of excision wounds in $\mathrm{CMC}+$ Sham -irradiation group (Figure 1). Oral administration of mice with different doses of HPD before exposure to shamirradiation showed a progressive increase in wound contraction with time depending on the HPD dose, which was evident by continuous shrinkage of wound area (Figures 1-7). A statistically significant wound contraction was observed on day 3 ( $\mathrm{p}<0.005), 6(\mathrm{p}<0.01$ and $9(\mathrm{p}<$ 0.05) after sham-irradiation for all HPD doses, in comparison with $\mathrm{CMC}+$ Sham -irradiation group (Figures 1-7). The degree of wound contraction increased with the increase in hesperidin dose up to $100 \mathrm{mg} / \mathrm{kg}$ when compared with other doses. A further increase in HPD dose did not alter this pattern significantly. However, hesperidin treatment caused an early closure of wounds when compared to $\mathrm{CMC}+$ Sham - irradiation group (Figures 1-
7). The CMC administration led to a thick scab formation, whereas HPD treatment resulted in a dose dependent reduction in the scab formation with increasing dose. The scab formation was completely absent for $100 \mathrm{mg} / \mathrm{kg}$ HPD and higher doses.

Exposure of whole body of the animals to 6 Gy irradiation resulted in a significant delay in the wound contraction at all post-irradiation times (Figures 1-7). Irradiation caused formation of a thick scab in CMC+ Irradiation group, whereas treatment of animals with different doses of hesperidin resulted in a progressive reduction in the scab formation, which was thinner and fell earlier when compared to CMC+ Irradiation group. The scab formation was almost absent in the animals treated with $100 \mathrm{mg} / \mathrm{kg}$ hesperidin before 6 Gy irradiation. Oral treatment of mice with different doses of hesperidin enhanced wound contraction in a HPD dose dependent manner and $10 \mathrm{mg} / \mathrm{kg}$ b. wt. HPD treatment did not have much effect although wound contraction was higher than 6 Gy alone (Figure 1). When HPD dose was further increased the wound contraction increased further and a maximum increase in wound contraction was observed in those animals receiving $100 \mathrm{mg} / \mathrm{kg}$ HPD (Figure 4). The wound contraction was significantly greater at $3(\mathrm{p}<0.005), 6(\mathrm{p}<0.01), 9(\mathrm{p}<$ $0.01), 12(\mathrm{p}<0.05)$ and $15(\mathrm{p}<0.05)$ days post-irradiation in the animals treated with $100 \mathrm{mg} / \mathrm{kg}$ hesperidin before 6 Gy irradiation, when compared to $\mathrm{CMC}+$ Irradiation group, whereas contraction of wound was highest at 6-12 days at other doses of HPD (Figures 1-7).

Mean Wound Healing Time: A continuous decline in the wound size with the passage of time was observed in $\mathrm{CMC}+$ Sham-irradiation group (Figure 8). The complete closure of wounds was observed by day $18.7 \pm 0.61$ day post-irradiation in $\mathrm{CMC}+$ Sham-irradiation group. Treatment of mice with 10 or $20 \mathrm{mg} / \mathrm{kg}$ HPD did not alter the mean wound healing time significantly when compared with $\mathrm{CMC}+$ Sham-irradiation group. A further increase in HPD dose up to $50 \mathrm{mg} / \mathrm{kg}$ caused a marginal reduction in mean wound healing time when compared to sham-irradiation group. The greatest reduction in mean wound healing time $(16 \pm 0.36)$ was observed for 100 $\mathrm{mg} / \mathrm{kg} \mathrm{HPD}$, where the early healing of wounds was observed in comparison with the CMC+Sham-irradiation group (Figure 8). This reduction in the mean wound healing time for $100 \mathrm{mg} / \mathrm{kg}$ HPD was statistically significant $(\mathrm{p}<0.05)$ when compared to $\mathrm{CMC}+$ Irradiation group. A further increase in HPD dose did not reduce the mean wound healing time which remained almost similar to that of $\mathrm{CMC}+$ Sham-irradiation (Figure 8).

The whole-body exposure of mice to 6 Gy $\gamma$-radiation 


\section{Nursing \& Healthcare International Journal}

significantly delayed the complete closure of wounds as a result the mean wound healing time also increased (23.33 \pm 0.49 days) for CMC+Irradiation group (Figure 8). This increase in mean wound healing time was approximately 5 days in CMC + Irradiation group when compared to $\mathrm{CMC}+$ Sham-irradiation group. Oral administration of animals with different doses of HPD progressively curtailed the wound healing time and a maximum attrition in wound healing was recorded for $100 \mathrm{mg} / \mathrm{kg}$ hesperidin, where it reduced to $21.5 \pm 0.56$ days $(\mathrm{p}<0.03)$, whereas a borderline effect on the mean healing time was noticed at other doses of HPD when compared with CMC+Irradiation group although the difference was not statistically significant (Figure 8).

\section{Discussion}

The polyphenols, abundant in fruits and vegetables, have gained recognition for their antioxidant properties and their roles in protecting against chronic diseases such as cancer and cardiovascular diseases [33-41,46]. A wound is a discontinuity or break in skin associated with the disruption of structures and function of the underlying tissues and immediate steps are required by the wound tissue to restore the continuity and physiological functions to avoid any pathophysiological implications [31,47]. The healing processes need to go smoothly in such a way that it does not lead to any defect that shall affect the functioning of the tissue/s. The superficial incision wound on the skin are easy to heal and generally not defective unless underneath tissues are involved. However, deep excision wounds offer a challenge as their healing if not directed properly results in several complications and morbidity. Therefore, much care is required to direct proper healing of deep dermal wounded tissues using exogenous stimuli or agents that can guide the healing process to heal the wounds normally. The ionizing radiations adversely affect the wound healing processes and retard wound healing cascade leading to non-healing or defective wounds [914]. The supplemental dietary agents may be a useful paradigm to properly direct the repair and regenerative processes in the irradiated wounds. Therefore, the present study was carried out to elucidate the effect of different doses of hesperidin on healing of full thickness deep dermal excision wounds in mice whole body exposed to 6Gy of $\gamma$-radiation.

Wound healing is an orderly process that proceeds in a well-orchestrated manner after injury. It starts from inflammatory phase, which is triggered by the migration of neutrophils from the ruptured blood vessels followed by macrophages and lymphocytes at the wound site within 1-2 days [48,49]. This is followed by overlapping proliferative and maturation and remodeling phases which are characterized by several cellular and biochemical events that progress in tandem with each other [48-51]. The ionizing radiation has multiple negative effects on all these phases of wound healing [914]. Wound contraction is an important event of repair and regenerative processes and it can be measured precisely by taking measurements of deep dermal wound by video imaging regularly until complete healing of the wound $[12,14,15,18-20,31]$. Wound contraction is a dynamic phenomenon and it can be defined as the centripetal movement of the edges of a full thickness wound in order to facilitate closure of the defect $[12,14,15,18-20,31,52,53]$. The exposure of mice to $6 \mathrm{~Gy}$ retarded the healing of wound and this observed delay in wound contraction is in good agreement with earlier reports, where a similar retardation in wound healing has been reported [10,18-21,31]. Treatment of mice with different doses of hesperidin prior to whole body $6 \mathrm{~Gy}$ irradiation resulted in a dose-related acceleration in wound healing up to $100 \mathrm{mg} / \mathrm{kg}$, as is evident by an increased wound contraction and early closure of wounds in the HPD+Irradiation group. The topical application of hesperidin has been found to accelerate wound contraction and reduce wound healing time in full thickness cutaneous wounds in whole body mice exposed to 6 Gy $\gamma$-radiation in an earlier study [31]. Certain nutrient factors including ascorbic acid and curcumin have been reported to accelerated early repair and regeneration of irradiated wounds in a dose related manner and a maximum effect could be observed up to a certain dose [10,54]. Similarly, vitamin A supplementation and phenytoin sodium improved the acute radiationinduced delay in wound healing $[55,56]$. Ascorbic acid, curcumin and Nigella sativa extract have been reported to enhance healing of irradiated excision wounds in mice in different preclinical settings [14,15,18-21].

Wound healing involves a cascade of well-orchestrated biochemical and cellular events leading to the growth and regeneration of wounded tissue in a specific manner and the ionizing radiation have been reported to produce diverse array of negative effects on wound healing processes that includes diminished vascularity, impairment of the proliferate capacity of fibroblasts and hematopoietic cells and decreased collagen and DNA syntheses [14,18-21,57-60]. The retardation in wound healing after irradiation may be due to the negative effect of radiation on important events of repair and regeneration. Ionizing radiation induces severe damage to vital tissues, especially those with a high rate of cell division, such as hematopoietic tissues that play an 


\section{Nursing \& Healthcare International Journal}

essential role in healing of wounds [60]. The ionizing radiations have been reported to sustain inflammatory phase by secretion of inflammatory cytokines including IL-1, IL-3, IL-5, and IL8, decrease fibroblast proliferation that lead to reduced extra cellular matrix deposition, collagen and DNA syntheses, which result in the impaired wound healing or defective wound healing [14,18$21,57,61]$. The acceleration in wound repair and regeneration by hesperidin may be due to the neutralization of these negative effects in the present study. A similar effect has been observed earlier with ascorbic acid, curcumin and Nigella sativa extract $[14,18$ 21].

The exact mechanism of acceleration in wound healing after hesperidin treatment may not be due to a single mechanism, but it could me due to operation of multiple mechanisms during the healing of irradiated wounds. The presence of HPD may have scavenged the radiation induced free radicals thereby neutralizing their effect and accelerating the repair and regeneration of irradiated wounds. The hesperidin has been reported to scavenge free radicals in an earlier study [31]. Irradiation and wound healing have been reported to prolong inflammatory responses [61]. Pretreatment of mice with HPD may have curtailed the duration of inflammatory responses to the required minimum and would have thus helped in the early regeneration and repair of irradiated wound. HPD has been reported to suppress the activation of proinflammatory cytokines IL-1 $\beta$, IL-8, and TNF- $\alpha$ [62]. It is also possible that the presence of HPD treatment before irradiation would have blocked the radiationinduced inhibition of cell cycle regulatory protein mRNAs to increase the capacity of fibroblast and endothelial cell division, which are essential for repair and regeneration of wound. The hesperidin treatment before irradiation has been found to increase fibroblast proliferation and blood vessel formation [63]. Wounding and irradiation has been reported to activate the transcriptional activation of NF- $\mathrm{KB}$, COX-II and LOX $[13,64,65]$. Treatment of mice with HPD may have inhibited radiation-induced transcriptional activation of NF- $\mathrm{BB}, \mathrm{COX}-\mathrm{II}$ and LOX resulting in the early repair and regeneration of wounds. This is supported by the observation, where HPD has been reported to inhibit of NF- $\mathrm{\kappa B}$ and COX-II activation [66]. The HPD increases Nrf2 expression that would have increased the activation of keratinocyte growth factor and accelerated the repair and regeneration of irradiated wound [62,67]. Matrix metalloproteinases play a crucial role during repair and regeneration of wound, however their higher expression

after irradiation has a negative impact on healing processes and delay wound healing [68,69]. The HPD reduces the higher expression of matrix metalloproteinases leading to enhanced wound healing of the irradiated wound [69]. The HPD might have triggered the rise in collagen and DNA syntheses that would have helped in matrix remodelling and early repair of wound. HPD treatment may have also struck a balance between regeneration and apoptosis that are essential for wound repair which may have accelerated the repair and regeneration of wounds. HPD has been reported to enhance collagen and DNA syntheses in irradiated wounds [63]. HPD has been reported to reduce radiationinduced lipid peroxidation and increase the antioxidant status in the irradiated wound, which would have also helped in the early repair of irradiated wound in mice receiving HPD [70].

\section{Conclusions}

The present study demonstrates that hesperidin retards the radiation induced delay in healing of irradiated wounds in a dose dependent manner and the greatest augmentation in wound healing was observed for $100 \mathrm{mg} / \mathrm{kg}$. This healing effect of HPD is due to scavenging of radiation-induced free radicals, antiinflammatory and antioxidant activities and reduced lipid peroxidation. The augmentation in healing of irradiated wound may be also due to suppression of IL-1 $\beta$, IL-8, TNF- $\alpha, N F-\kappa B, C O X-I I$, LOX and matrix metalloproteinase activation by HPD after irradiation. The increase Nrf2 activity by HPD may have also contributed in the acceleration of repair and regeneration of irradiated wound in the present study. However further detailed studies are required to understand the clinical implications of these results.

\section{References}

1. Howell JD (2016) Early clinical use of the x-ray. Trans Am Clin Climatol Assoc 127: 341-349.

2. McLean AR, Adlen EK, Cardis E, Elliott A, Goodhead DT, et al. (2017) A restatement of the natural science evidence base concerning the health effects of lowlevel ionizing radiation. Proc Biol Sci 284(1862): 20171070.

3. Zhao JZ, Mucaki EJ, Rogan PK (2018) Predicting ionizing radiation exposure using biochemicallyinspired genomic machine learning. F1000Research 7: 233. 


\section{Nursing \& Healthcare International Journal}

4. Ahmad SS, Duke S, Jena R, Williams MV, Burnet NG (2012) Advances in radiotherapy. BMJ $\mathrm{Br}$ MedJ 345(1): e7765.

5. Hellevik T, Martinez Zubiaurre I (2014) Radiotherapy and the tumor stroma: the importance of dose and fractionation. Front Oncol 4: 1.

6. Steinhauser G, Brandl A, Johnson TE (2014) Comparison of the Chernobyl and Fukushima nuclear accidents: a review of the environmental impacts. Sci Total Environ 470-471: 800-817.

7. Ishikawa T (2017) Radiation doses and associated risk from the Fukushima nuclear accident: a review of recent publications. Asia Pacific Journal of Public Health 29(2): 18S-28S.

8. Kumar P, Jagetia GC (1994) A review of triage and management of burns victims following a nuclear disaster. Burns 20(5): 397-402.

9. Jagetia GC, Baliga MS (2003) Evaluation of the radioprotective effect of the leaf extract of Syzygium cumini (Jamun) in mice exposed to a lethal dose of $\gamma$-irradiation. Mol Nutri Food Res 47(3): 181-185.

10. Jagetia GC, Rajanikant GK (2004) Role of curcumin, a naturally occurring phenolic compound of turmeric in accelerating the repair of excision wound, in mice whole-body exposed to various doses of $\gamma$-radiation. J Surg Res 120(1): 127-138.

11. Jarrett DG, Sedlak RG, Dickerson WE, Reeves GI (2007) Medical treatment of radiation injuriesCurrent US status. Radiation Measurements 42(6-7): 1063-1074.

12. Jagetia GC, Rajanikant GK (2012) Acceleration of wound repair by curcumin in the excision wound of mice exposed to different doses of fractionated $\gamma$ radiation. Int Wound J 9(1): 76-92.

13. Ryan JL (2012) Ionizing radiation: the good, the bad, and the ugly. J Invest Dermatol 132(3): 985-993.

14. Jagetia GC, Ravikiran PB (2015) Acceleration of wound repair and regeneration by Nigella sativa in the deep dermal excision wound of mice whole body exposed to different doses of $\gamma$-radiation. American Research Journal of Medicine and Surgery 1(3): 1-17.

15. Jagetia GC, Rajanikant GK (2017) Topical application of curcumin augments healing of deep dermal excision wound of mice exposed to whole-body gamma radiation. Journal of Nursing \& Healthcare 2(1): 1-7.

16. Spitz DR, Hauer Jensen M (2014) Ionizing radiationinduced responses: where free radical chemistry meets redox biology and medicine. Antioxid Redox Signal 20(9): 1407-1409.

17. Maier P, Hartmann L, Wenz F, Herskind C (2016) Cellular pathways in response to ionizing radiation and their targetability for tumor radiosensitization. Int J Mol Sci 17(1): 102.

18. Jagetia GC, Rajanikant GK, Rao KVNM (2003) Modulation of radiation-induced delay in the wound healing by ascorbic acid in mice exposed to different doses of hemi-body $\gamma$-radiation. Wounds 15: 324-338.

19. Jagetia GC, Rajanikant GK, Rao SK (2003) Evaluation of the Effect of Ascorbic Acid Treatment on Wound Healing in Mice Exposed to Different Doses of Fractionated Gamma Radiation. Radiation Research 159: 371-80.

20. Jagetia GC,Rajanikant GK (2005) Curcumin treatment enhances the repair and regeneration of wounds in mice exposed to hemibody gamma-irradiation. Plast Reconstruct Surg 115(2): 515-528.

21. Jagetia GC, Rajanikant GK, Rao KVNM (2007) Ascorbic acid increases healing of excision wounds of mice whole body exposed to different doses of gammaradiation Burns 33(4): 4844-4894.

22. Flukiger FA, Hanbury D (1986) In Pharmacographia A History of the Principle Drugs of vegetable Origin. International Book Distributors: Delhi. India: 104105.

23. Kanes K, Tisserat B, Berhow M, Vandercook C (1993) Phenolic composition of various tissues of Rutaceae species. Phytochemistry 32(4): 967-974.

24. Emim JADS, Oliveria AB, Lapa AJ (1994) Pharmacological evaluation of the anti-inflammatory activity of a citrus bioflavonoid, hesperidin and the isoflavanoids duartin and claussequinone, in rats and mice. J Pharm Pharmacol 46(2): 118-122.

25. Horowitz RM, Gentili B (1963) Flavonoids of citrusVI: The structure of neohesperidose. Tetrahedron 19(5): 773-782.

26. Kawaguchi K, Mizuno T, Aida K, Uchino K (1997) Hesperidin as an inhibitor of lipases from porcine 


\section{Nursing \& Healthcare International Journal}

pancreas and Pseudomonas. Biosci Biotech Biochem 61(1): 102-114.

27. Nogata Y, Sakamoto K, Shiratsuchi H, Ishii T, Yano M, et al. (2006) Flavonoid composition of fruit tissues of citrus species. Biosci Biotechnol Biochem 70(1): 178192.

28. Galati EM, Monforte MT, Kirjavainen S, Forestieri AM, Trovato A, et al. (1994) Biological effects of hesperidin, a citrus flavonoid. (Note I): antiinflammatory and analgesic activity. Farmaco 40(11): 709-712.

29. Bae EA, Han MJ, Lee M, Kim DH (2000) In vitro inhibitory effect of some flavonoids on rotavirus infectivity. Biol Pharmaceut Bull 23(9): 1122-1124.

30. Ohtsuki K, Abe A, Mitsuzumi H, Kondo M, Uemura K, et al. (2003) Glucosyl hesperidin improves serum cholesterol composition and inhibits hypertrophy in vasculature. J Nutr Sci Vitaminol 49(6): 447-450.

31. Jagetia GC, Rao KVNM (2017) Topical application of hesperidin, a citrus bioflavanone accelerates healing of full thickness dermal excision wounds in mice exposed to 6 Gy of whole body $\gamma$-Radiation. Clin Res Dermatol OA 4(3): 1-8.

32. Felicia VS, Najla G, Ann FC, Madeleine M, Kenneth KC (1996) Inhibition of Human Breast cancer cell proliferation and delay of mammary tumorigenisis by flavonoides and citrus juices. Nutr Cancer 26(2): 167181.

33. Ameer B, Weintraub RA, Johnson JV, Yost RA, Rouseff RL (1996) Flavanone absorption after naringin, hesperidin, and citrus administration. Clin Pharmacol Ther 60(1): 34-40.

34. Miyagi Y, Om AS, Chee KM, Bennink MR (2000) Inhibition of azoxymethane-induced colon cancer by orange juice. NutrCancer 36(2): 224-229.

35. Vabeiryureilai M, Lalrinzuali K, Jagetia GC (2015) Determination of anti-inflammatory and analgesic activities of a citrus bioflavanoid, hesperidin in mice. Immunochemistry \& Immunopathology 1(2): 107.

36. Kohno H, Taima M, Sumida T, Azuma Y, Ogawa H, et al. (2001) Inhibitory effect of mandarin juice rich in $\beta$ cryptoxanthin and hesperidin on 4(methylnitrosamino)-1-(3-pyridyl)-1-butanoneinduced pulmonary tumorigenesis in mice. Cancer Lett 174(2): 141-150.
37. Yamamoto M, Jokura $H$, Suzuki A, Hase T, Shimotoyodome A (2013) Effects of continuous ingestion of hesperidin and glucosyl hesperidin on vascular gene expression in spontaneously hypertensive rats. J Nutr Sci Vitaminol (Tokyo) 59(5): 470-473.

38. Cincin ZB, Unlu M, Kiran B, Bireller ES, Baran Y, et al. (2015) Anti-proliferative, apoptotic and signal transduction effects of hesperidin in non-small cell lung cancer cells. Cell Oncol 38(3): 195-204.

39. Dobiaš L, Petrová M, Vojtko R, Kristová V (2016) Long-term treatment with hesperidin improves endothelium-dependent vasodilation in femoral artery of spontaneously hypertensive rats: The involvement of NO-synthase and $\mathrm{Kv}$ channels. Phytother Res 30(10): 1665-1671.

40. Chiba $\mathrm{H}$, Uehara $\mathrm{M}, \mathrm{Wu}$ J, Wang $\mathrm{X}$, Masuyama $\mathrm{R}$, et al. (2003) Hesperidin, a citrus flavonoid, inhibits bone loss and decreases serum and hepatic lipids in overtiectimized mice. J Nutr 133(6): 1892-1897.

41. Kawaguchi K, Maruyama H, Kometani T, Kumazawa Y (2006) Suppression of collagen-induced arthritis by oral administration of the citrus flavonoid hesperidin. Planta medica 72(5): 477-479.

42. Crespo ME, Galvez J, Cruz T, Ocete MA, Zarzuelo A (1999) Anti-inflammatory activity of diosmin and hesperidin in rat colitis induced by TNBS. Planta Medica 65(7): 651-653.

43. Oliveira VM, Carneiro AL, Cauper GS, Pohlit AM (2009) In vitro screening of Amazonian plants for hemolytic activity and inhibition of platelet aggregation in human blood. Acta Amazonica 39(4): 973-980.

44. Marín L, Miguélez EM, Villar CJ, Lombó F (2015) Bioavailability of dietary polyphenols and gut microbiota metabolism: antimicrobial properties. Bio Med Res Int 2015: 905215.

45. Kawabe M, Tamano S, Shibata MA, Hirose M, Fukushima S, et al. (1993) Subchronic toxicity study of methyl hesperidin in mice. Toxicl Lett 69(1): 37-44.

46. Agrawal YO, Sharma PK, Shrivastava B, Ojha S, Upadhya HM, et al. (2014) Hesperidin produces cardioprotective activity via PPAR-c pathway in ischemic heart disease model in diabetic rats. PLoS ONE 9(11): e111212. 


\section{Nursing \& Healthcare International Journal}

47. Enoch S, Leaper DJ (2008) Basic science of wound healing. Surgery 26: 36-37.

48. Broughton G, Janis JE, Attinger CE (2006) The basic science of wound healing. Plast Reconst Surg 117(7): 12S-34S.

49. Minutti CM, Knipper JA, Allen JE, Zaiss DM (2017) Tissue-specific contribution of macrophages to wound healing. Semin Cell Dev Biol 61: 3-11.

50. Velazquez OC (2007) Angiogenesis and vasculogenesis: Inducing the growth of new blood vessels and wound healing by stimulation of bone marrow-derived progenitor cell mobilization and homing. J Vascul Surg 45 Suppl A: A39-47.

51. Chong DC, Yu Z, Brighton HE, Bear JE, Bautch VL (2017) Tortuous microvessels contribute to wound healing via sprouting angiogenesis. Arterioscl Thromb Vascul Biol 37(10): 1903-1912.

52. Tejero Trujeque R (2001) How do fibroblasts interact with the extracellular matrix in wound contraction? J Wound Care 10(6): 237-242.

53. Golberg A, Bei M, Sheridan RL, Yarmush ML (2013) Regeneration and control of human fibroblast cell density by intermittently delivered pulsed electric fields. Biotechnol Bioeng 110(6): 1759-1768.

54. Jagetia GC, Rajanikant GK, Baliga MS, Rao KV, Kumar P (2004) Augmentation of wound healing by ascorbic acid treatment in mice exposed to $\gamma$-radiation. IntJRadiat Biol 80(5): 347-354.

55. Levenson SM, Gruber CA, Rettura GI, Gruber DK, Demetriou AA, et al. (1984) Supplemental vitamin A prevents the acute radiation-induced defect in wound healing. Ann Surg 200(4): 494-512.

56. Song S, Cheng T (1997) The effect of systemic and local irradiation on wound macrophage and repair promoting action of phenytion sodium. Zhonghma Yi Xue Za Zhi 77(1): 54-57.

57. Rudolph R, Vande Berg J, Schneider JA, Fisher JC, Poolman WL (1988) Slowed growth of cultured fibroblasts from human radiation wounds. Plastic Recon Surg 82(4): 669-677.

58. Doyle JW, Li Y, Salloum A (1996) The effects of radiation on neo-vascularization in a rat model. Plast Reconstr Surg 98(1): 129-35.
59. Gu Q, Wang D, Cui C, Gao Y, Xia G, et al. (1998) Effects of radiation on wound healing. J Environ Pathol Toxicol Oncol 17(2): 117-123.

60. Zelman D, Song IC, Porteous DD, Bromberg BE (1969) The effect of total body irradiation on wound healing and hematopoietic system. Bull NY Acad Med 45(3): 293-300.

61. Bray FN, Simmons BJ, Wolfson AH, Nouri K (2016) Acute and chronic cutaneous reactions to ionizing radiation therapy. Dermatol Ther (Heidelb) 6(2): 185206.

62. Parhiz H, Roohbakhsh A, Soltani F, Rezaee R, Iranshahi M (2015) Antioxidant and anti-inflammatory properties of the citrus flavonoids hesperidin and hesperetin: an updated review of their molecular mechanisms and experimental models. Phytother Res 29(3): 323-331.

63. Jagetia GC, Rao KVNM (2018) Hesperidin, a citrus bioflavonoid potentiates repair and regeneration of deep dermal excision wounds of mice whole body exposed to different doses of ${ }^{60} \mathrm{Co} \gamma$-radiation. Clin Dermatol OA 3(2): 000147.

64. Zhou D, Brown SA, Yu T, Chen G, Barve S, et al. (1999) A high dose of ionizing radiation induces tissuespecific activation of nuclear factor-kappaB in vivo. Radiat Res. 151(6): 703-709.

65. Gaddipati JP, Sundar SV, Calemine J, Seth P, Sidhu GS, et al. (2003) Differential regulation of cytokines and transcription factors in liver by curcumin following hemorrhage/resuscitation. Shock 19(2): 150-156.

66. Ghorbani A, Nazari M, Jeddi-Tehrani M, Zand H (2012) The citrus flavonoid hesperidin induces p53 and inhibits NF- $\mathrm{\kappa B}$ activation in order to trigger apoptosis in NALM-6 cells: involvement of PPAR $\gamma$ dependent mechanism. Eur J Nutr 51(1): 39-46.

67. Elavarasan J, Velusamy P, Ganesan T, Ramakrishnan SK, Rajasekaran D, et al. (2012) Hesperidin-mediated expression of Nrf2 and upregulation of antioxidant status in senescent rat heart. J Pharm Pharmacol 64(10): 1472-1482.

68. Wang PH, Huang BS, Horng HC, Yeh CC, Chen YJ (2018) Wound healing. J Chin Med Assoc 81(2): 94101.

69. Lee HJ, Im AR, Kim SM, Kang HS, Lee JD, et al. (2018) The flavonoid hesperidin exerts anti-photoaging 
effect by downregulating matrix metalloproteinase (MMP)-9 expression via mitogen activated protein kinase (MAPK)-dependent signaling pathways. BMC Compl Altern Med 18(1): 39.
70. Jagetia GC, Rao KVNM (2015) Hesperidin, A citrus bioflavonoid reduces the oxidative stress in the skin of mouse exposed to partial body $\gamma$-radiation. Transcriptomics 3(2). 